\title{
Party leaders and voter responses to political terrorism
}

\author{
Benny Geys ${ }^{1}$ (D) Øystein Hernæs ${ }^{2}$
}

Received: 29 April 2019 / Accepted: 26 February 2020 / Published online: 7 March 2020

(C) The Author(s) 2020

\begin{abstract}
In this article, we study the political implications of terrorism rooted in extremist political ideologies. Our data uniquely allow studying the potential role of party leader evaluations on political outcomes, including voter turnout and vote choice. To strengthen causal identification, we combine an event-study framework with the fact that Norwegians were affected personally to differing degrees by the 22 July 2011 terror attack because of variation in the victims' municipalities of residence. Our main findings suggest that extreme right-wing terrorism influences party vote intentions and evaluations of political leaders strongly in the short run, as well as party choice in actual elections in the longer run. We document shifts within Norway's left-right political blocs rather than shifts between those blocs frequently observed following religious/separatist violence.
\end{abstract}

Keywords Terrorism · Public opinion · Vote choice $\cdot$ Party leadership $\cdot$ Turnout $\cdot$ Norway

\section{Introduction}

Terrorism - commonly defined as "the premeditated use, or threat to use, violence by individuals or subnationals to obtain political or social objectives through the intimidation of a large audience beyond that of the immediate victims" (Enders and Sanders 2012, p. 4) can have important socio-economic consequences, as well as affecting micro-level attitudes and public opinion (Berrebi and Klor 2008; Finseraas and Listhaug 2013; Merolla and Zechmeister 2013; Getmansky and Zeitzoff 2014; Peffley et al. 2015; Hirsch-Hoefler et al. 2016). Key findings in the rapidly expanding academic literature show that terrorist events tend to strengthen support for right-wing parties (Kibris 2011; Berrebi and Klor 2008; Getmansky and Zeitzoff 2014), heighten public concerns over future similar events (Bozzoli

Electronic supplementary material The online version of this article (https://doi.org/10.1007/s1112 7-020-00789-3) contains supplementary material, which is available to authorized users.

Benny Geys

Benny.Geys@bi.no

Øystein Hernæs

o.m.hernas@ frisch.uio.no

1 BI Norwegian Business School, Nydalsveien 37, 0484 Oslo, Norway

2 The Ragnar Frisch Centre for Economic Research, Gaustadalleen 21, 0349 Oslo, Norway 
and Mueller 2011; Finseraas and Listhaug 2013; Hirsch-Hoefler et al. 2016; Geys and Qari 2017), increase anti-immigrant sentiments and factional 'radicalization' (Echebarria-Echabe and Fernandez-Guede 2006; Sinclair and LoCicero 2010; Finseraas et al. 2011; Gould and Klor 2016; Hirsch-Hoefler et al. 2016) and boost philanthropic behavior (Berrebi and Yonah 2016). Evidence that such events trigger more widespread support for stricter security and defense policies remains mixed (Finseraas and Listhaug 2013; Economou and Kollias 2019), while terrorism's influence on institutional and social trust appears at best shortlived (Arvanitidis et al. 2016; Geys and Qari 2017). ${ }^{1}$

Terrorism can be inspired by religious (e.g., ISIS) or separatist (e.g., ETA) movements as well as by extremist political ideologies (e.g., Rote Armee Fraction, or neo-Nazi/white supremacist groups) (Shughart 2006). It likewise can make use of a wide range of tacticsincluding bombings, shootings, and intentional vehicular assaults - which tend to have distinctive death and injury profiles and translate into diverging numbers of disability adjusted lives (or life years) lost (Arce 2019). In this article, we study one instance of an extreme right-wing terrorist act by analyzing the causal effect of Anders Behring Breivik's attack in Norway on 22 July 2011. That attack—in which 77 people were killed—was directed at the Norwegian government in general, and more particularly the Labour Party (which has been the largest political party in Norway since 1927 and was in power at the time of the attack). When questioned by the police, the terrorist stated that he had wanted to hurt the Labour Party specifically because he regarded it as responsible for the ongoing "deconstruction" of Norwegian culture brought about by the "mass import" of Muslims (Oslo Tingrett 2011). We investigate how that politically inspired terrorist event impacted voters' party leader evaluations and party choices by exploiting data from actual elections as well as a large number of public opinion polls.

Our detailed dataset provides a unique opportunity for studying the potential role of party leader assessments following terrorist events. With the growing personalization of party politics and strong mass media focus on party leaders (McAllister 2016), voters might indeed interpret the response to terror of any given political party at least in part through its leader. Opinions about party leaders in the aftermath of a terrorist event thus may provide an important causal mechanism behind the public's response in terms of political outcomes (e.g., turnout and party support). That transmission channel is likely to arise for two main reasons. On the one hand, although the timing and location of terrorist events are outside the control of politicians, Ashworth et al. $(2018$, p. 37) show that "such events can affect electoral outcomes, even if voters are rational and have instrumental preferences". The underlying argument is that terrorist events create an opportunity to learn new information about (the expected quality of) politicians, which affects expectations of future government performance and thereby individual's vote choices. On the other hand, party leaders may have "very different styles of crisis communication" in the aftermath of a terrorist event, which can have a substantial impact on their electoral fortunes (Sinkkonen 2016, p. 326). Voters' perceptions of party leaders and their response to the event thus

\footnotetext{
1 A closely related literature investigates the economic impact of terrorist activity. Such studies analyze, for instance, disruptions of trade relations (Bandyopadhyay et al. 2018), economic growth (Gaibulloev and Sandler 2011), tourism (Neumayer and Plümper 2016) and perceived financial well-being (Gaibulloev et al. 2019), as well as trust's indirect role in those processes (Blomberg et al. 2011). A vast literature also exists on the determinants of terrorism. Excellent reviews of this work include Krieger and Meierrieks (2011) and Gassebner and Luechinger (2011), while more recent contributions include studies on the influence of natural distasters (Berrebi and Ostwald 2011), political proximity to major Western powers (Gaibulloev and Sandler 2019), reforms improving ethnic inclusion (Gleditsch and Polo 2016), and oil wealth (Piazza 2016).
} 
might influence party preferences and vote choices in subsequent elections. We are, to the best of our knowledge, the first contributors to the relevant literature to include party leaders as a key part of the research design. ${ }^{2}$

Our empirical approach relies on two different strategies. First, we employ detailed polling data before and after the attack in an event-study framework, which exploits the fact that the attack was entirely unexpected and occurred in the middle of summer holidays (for a similar approach, see for instance, Finseraas and Listhaug 2013; Geys and Qari 2017). Such an approach becomes less credible, however, when the time frame under analysis is longer since many other things may have happened in the meantime (which might undermine a causal interpretation of the findings). To study actual voting behaviour, which is observed only at longer intervals, our second empirical approach therefore exploits the fact that Norwegians were affected personally to different extents since the victims were from different parts of the country. Although the country as a whole was shocked by the attacks, variation in the victims' municipalities of residence allows us to provide stronger causal identification regarding how people in a local community respond to the killing of one of the members of that community - using the development over time in municipalities from which victims did not originate as a reference group in a difference-in-differences framework (for a similar approach, see Gartner et al. 1997; Gartner 2014). Being affected personally by the attack may thereby influence party choices through (de)mobilisation, by shifting one's vote owing to preference changes or to expressive voting motives (see below).

Our main findings first of all suggest that exposure to extreme right-wing terrorism influences voters' intended party choice strongly in the short run, and also affects party choices in actual elections in the longer run. Interestingly, we specifically document shifts within the left-right political blocs in Norway rather than shifts between those blocs frequently observed following religious/separatist violence. The effects may in part be driven by changes in voter turnout as, in line with expectations from political mobilization theories and earlier findings by Robbins et al. (2013), we find a statistically significant effect of terrorism on voter turnout. Secondly, the terrorist event's influence on performance assessments of the leader of the Labour Party (also Norway's prime minister at the time) was very strong and positive, but weaker for all other party leaders except the right-wing Progress Party (whose leader's performance assessment witnessed a substantial decline). Consistent with growing personalization of party politics, the observed changes in leader evaluations mirror the stronger (weaker) voter support for the Labour (Progress) Party in the aftermath of the attacks as well as the weaker (stronger) voter support for other left-wing (center-right) parties. Those results indicate an important role for party leader evaluations in individual voters' responses to terrorist events, likely occurring from a combination of leaders themselves shaping voters' reactions as well as playing into and being shaped by those reactions.

A number of previous studies evaluated empirically the impact on Norwegian society of '22 July' (as the attack became known in Norway). Most of those studies focus on relatively short-term impacts outside the immediate political sphere. Wollebæk et al. (2012)

\footnotetext{
2 That is not to say that political leaders have been absent from the related literature. Several studies have, for instance, analyzed how terrorism affects the evaluation of political leaders' desired traits (Merolla and Zechmeister 2009a, b; Holman et al. 2016) as well as how political elites' actions shape the 'rally around the flag' effect often triggered by terrorist events (Baum 2002; Chowanietz 2011). Closest to our work is the study by Montalvo (2011), which explicitly discusses political leaders' handling of the 2004 Madrid bombings in relation to voters' subsequent vote choices. Still, he does not have access to information about party leader assessments, which is a unique feature of our dataset.
} 
find short-term positive effects on Norwegians' trust and civic engagement, while Jakobsson and Blom (2014) show that attitudes towards immigrants improved immediately after the attack. ${ }^{3}$ Experimental work by Birkelund et al. (2019) indicates, however, that Norweigans' reactions did not translate into less discrimination against ethnic minorities on the national job market three to five months after the event. The only study examining a longer time-frame is Kolås (2017), which finds no evidence of strong policy implications of the attack in the years following 22 July. Our analysis differs from that body of work in terms of its research questions (i.e., the focus herein on party leadership and political outcomes), empirical approach (i.e., exploitation of victims' geographical locations and the combination of short- and longer-term impacts) and datasets (using both novel survey data and actual election results).

\section{Data}

Our analysis builds on three main sources of data. First, we collected information on our central political outcome variables from two different sources. Municipality-level data on party vote shares and voter turnout rates covering the 1999-2013 period were obtained from Kommunedatabasen ('Municipality Database') — a compendium of Norwegian local data administered by the Norwegian Social Science Data Services (NSD). We expanded that information with individual-level survey data covering the period from January 2010 to December 2011 (original data collected by Respons Analyse AS). That source contains repeated cross-sectional observations representative of the Norwegian population and is available on a monthly basis with two exceptions: (1) no surveys were conducted in July 2010 and July 2011 (owing to the company's annual summer break) and (2) weekly surveys conducted throughout August and early September ahead of the 12 September 2011 local elections. Each survey contains basic background information about the respondents (e.g., age, gender, education, income and municipality of residence) as well as key questions on intended vote choices if elections were held 'tomorrow' and evaluations of Norway's political elite. ${ }^{4}$

Second, we collected information on the hometowns of the victims of the terrorist attack from two sources. Most of the victims were participants at the summer camp of the Norwegian Labour Party's youth organization, a yearly gathering of young party members from around the country. The home municipalities of the 77 individuals who died are collected from Stormark (2011), and show that 52 municipalities had at least one inhabitant killed. As the main site of the attack was the island of Utøya, we also collected information on the home municipalities of the 66 injured people and 585 survivors suffering no physical harm on the island (Norwegian Directorate of Health 2012). Data on the municipalities with inhabitants present on Utøya were acquired from

\footnotetext{
${ }^{3}$ Using data from telephone interviews, Thoresen et al. (2012) suggest that the attacks induced immediate negative emotional responses, especially in terms of sadness, feelings of unreality and jumpiness. Yet, as the data were collected four to five months after the event, concerns arise regarding recall bias (as recognized by the authors).

${ }^{4}$ Exact question wordings were as follows (translated from the original Norwegian): "If there was a national election (to the Storting) tomorrow, which party would you vote for?" (answer options include all major national parties, as well as 'don't know' and 'will not vote'); "How do you assess the work of the following party leaders? You can answer by scoring them from 1 to 6 , where 1 is the lowest grade and 6 is the best grade."
} 
Fig. 1 Distribution of victims across Norway. Note: The figure presents the distribution of victims across Norway. $T 1$ and $T 2$ refer to municipalities' 'treatment' status (i.e. inhabitants killed [ $T 1$ ], inhabitants present but survived [T2], and no inhabitants present [Control])

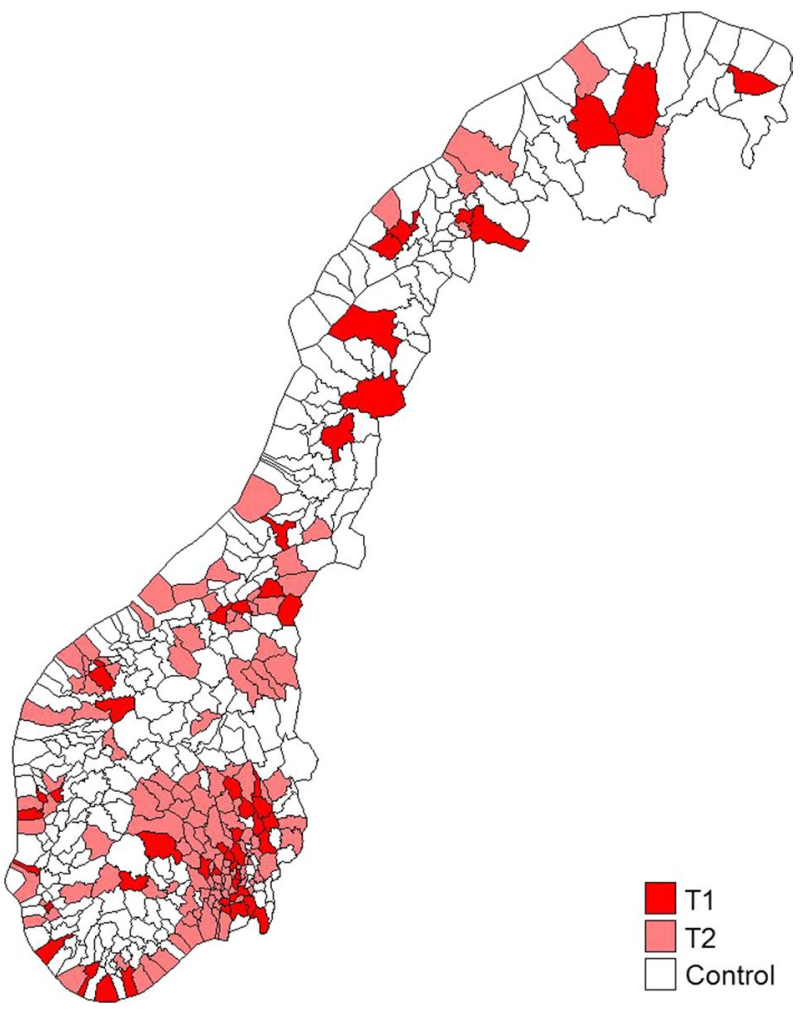

the 18 county governors, who disbursed funds to provide any necessary treatment and support for those individuals in their respective municipalities. While 127 municipalities had surviving inhabitants, we do not have information about the number of survivors from those individual municipalities. The distribution of victims across Norway is shown in Fig. 1. Throughout the analysis, municipalities whose inhabitants were killed in the attack will be considered as having been 'treated' most severely by the event (also see below), and are referred to as $T 1$. Municipalities from which inhabitants were present on the island but of whom all survived are referred to as $T 2$. Thus, $T 1$ and $T 2$ are mutually exclusive.

Finally, we expanded our dataset by adding several municipality-level socio-demographic characteristics from Kommunedatabasen. Table 1 reports descriptive statistics for several pre-attack municipality-level variables on the basis of future 'treatment' status: i.e., inhabitants killed (T1), inhabitants present but survived (T2), and no inhabitants present (Control). The table indicates considerable oversampling of large, densely populated municipalities in the treatment groups. That is not surprising since such municipalities likely had more participants in the Labour Party's youth camp because of their population sizes and easier travel routes. Nevertheless, that feature is unproblematic for our analysis since all permanent differences between municipalities will be absorbed by the inclusion of municipality fixed effects in the estimation models (see below). Other background variables show no distributional differences. Crucially, those similarities include vote shares of the left-wing Labour Party and right-wing Progress 
Table 1 Descriptive statistics 2010 (pre-treatment) by future treatment status

\begin{tabular}{|c|c|c|c|c|c|c|}
\hline & \multicolumn{2}{|l|}{$\mathrm{T} 1$} & \multicolumn{2}{|l|}{$\mathrm{T} 2$} & \multicolumn{2}{|c|}{ Control } \\
\hline & Mean & $\mathrm{SD}$ & Mean & $\mathrm{SD}$ & Mean & $\mathrm{SD}$ \\
\hline Population & 41.77 & $(89.600)$ & 13.43 & $(13.703)$ & 3.94 & $(3.770)$ \\
\hline Population density & 0.73 & $(0.203)$ & 0.62 & $(0.253)$ & 0.41 & $(0.259)$ \\
\hline Income (USD 1000) & 51.22 & $(5.081)$ & 50.15 & $(5.092)$ & 46.99 & (4.196) \\
\hline Unemployment males, $\%$ & 2.69 & $(0.499)$ & 2.49 & $(0.707)$ & 2.60 & $(1.122)$ \\
\hline Public sector, share of labor force & 0.21 & $(0.056)$ & 0.20 & $(0.051)$ & 0.25 & $(0.069)$ \\
\hline Health and social, share of labor force & 0.21 & $(0.031)$ & 0.20 & $(0.032)$ & 0.21 & $(0.035)$ \\
\hline Female workers, share of labor force & 0.47 & $(0.012)$ & 0.47 & $(0.013)$ & 0.46 & $(0.015)$ \\
\hline Education, average years of schooling & 11.96 & $(0.429)$ & 11.79 & $(0.342)$ & 11.55 & $(0.321)$ \\
\hline Disability recipients, share of inhabitants & 0.07 & $(0.016)$ & 0.07 & $(0.017)$ & 0.07 & $(0.022)$ \\
\hline Welfare recipients, share of inhabitants & 0.03 & $(0.008)$ & 0.02 & $(0.007)$ & 0.03 & $(0.011)$ \\
\hline Labour party vote share 2007 & 0.30 & $(0.094)$ & 0.31 & $(0.113)$ & 0.30 & $(0.144)$ \\
\hline Labour party vote share 2009 & 0.37 & $(0.083)$ & 0.36 & $(0.087)$ & 0.34 & $(0.091)$ \\
\hline Progress party vote share 2007 & 0.18 & $(0.075)$ & 0.16 & $(0.095)$ & 0.10 & $(0.096)$ \\
\hline Progress party vote share 2009 & 0.24 & $(0.053)$ & 0.24 & $(0.060)$ & 0.22 & $(0.061)$ \\
\hline$N$ & 52 & & 122 & & 249 & \\
\hline
\end{tabular}

Population density is the share of inhabitants in a municipality living in an "urban settlement" (characterised by at least 200 persons and with a minimum distance of $50 \mathrm{~m}$ between buildings); income is average gross income of all persons aged 17 or more (converted to USD with an exchange rate of 1 USD $=6.5$ NOK); unemployment is average percentage of men with no earnings in a given year; public sector labor force is the share of workers employed in municipal or state administration; health and social denotes share of workers employed in both public and private health and social services

Party, which limits potential concerns that the distribution of victims merely reflects the electoral strength of the Labour Party (we return to that issue below).

\section{Empirical approach and identification strategy}

Our analysis of party choices at the individual level builds on an event-study framework comparing political outcomes before and after the 22 July attack. That is a valid approach in our setting since the attack was fully unexpected, such that the timing of individuals' survey responses can be considered to be exogenous to the event under study. The empirical model here takes the following basic form (with $i$ indicating individuals):

$$
y_{i}=\beta_{1} 22 \text { July }_{i}+\beta_{2} \text { Weeks }+\beta_{3} 22 \text { July }_{i} * \text { Weeks }+\delta_{m}+\gamma_{t}+\epsilon_{i}
$$

The dependent variable reflects respondents' intended vote choices if elections were organized 'tomorrow'. Our main independent variable $\left(22 J u l y_{i}\right)$ is set equal to 1 for respondents answering after the 22 July attack ( 0 otherwise). Its coefficient indicates the extent to which the 22 July event caused a shift in individual respondents' attitudes. We also enter a linear time trend (Weeks) centered around the week of the attack, and its interaction with $22 J u l y_{i}$. Those two variables control for any potential pre-attack trend in individual attitudes. It furthermore assesses whether the terrorist attack induced a shift in the trend, rather than changing only the levels of our attitudinal variables. In our main 
specification, Weeks takes values from - 78.5 (i.e., January 2010) to 22 (i.e., December 2011 ) as this covers the entire time period available for analysis (window selection is discussed further below).

Yet, as mentioned, exclusive reliance on the temporal shock may not be adequate for causal interpretation of the findings when we move to longer-term effects observed in actual election results. We therefore follow Gartner et al. (1997) and Gartner (2014) in additionally exploiting the geographical distribution of the victims' hometowns across the Norwegian territory.That specification allows employing a difference-in-differences (DiD) research design with two treatments varying among municipalities, i.e., whether one or more municipal inhabitants were killed in the attack $(T 1)$, and whether one or more inhabitants were present on Utøya but all survived (T2). Those considerations lead to the following baseline empirical model (with $m$ for municipality and $t$ for time):

$$
y_{m t}=\beta_{1} T 1_{m t}+\beta_{2} T 2_{m t}+\delta_{m}+\gamma_{t}+\epsilon_{m t}
$$

In Eq. (2), $y_{m t}$ measures our municipality-level political outcomes of interest, i.e., voter turnout decisions and party choices. $T 1$ and $T 2$ are indicator variables set equal to 0 for all municipalities and all time periods up to and including the third quarter of 2011, and switch to 1 in the remaining periods for those municipalities from which at least one inhabitant was killed in the attack (T1) or survived the attack at Utøya (T2). All models include municipality fixed effects $\delta_{m}$ and time fixed effects $\gamma_{t}$; we cluster standard errors at the municipality level. As robustness checks, we also enter several time-varying individual, municipality, or both covariates. The same approach likewise is employed when looking at voters' evaluations of Norway's political elite. Even though that analysis relies on individual-level survey data, the availability of only three data points (i.e., June 2010, June 2011 and December 2011) makes it impossible to implement an event-study analysis of those data.

It is important to note that our approach does not require that municipalities with victims represent a random sample of all municipalities, as many practical, socioeconomic and political elements might be correlated with a municipality being represented at the Labour Party's youth camp. Rather, the key identifying assumption is that conditional on municipality and time fixed effects (as well as other covariates), participation at the camp and the geographical distribution of the victims are uncorrelated with the determinants of individual- and aggregate-level political outcomes around the attack. One way to evaluate the validity of the difference-in-differences research design is to ask whether trends in treated and non-treated groups are parallel prior to the event under analysis. In Fig. 2, we provide a series of graphical illustrations that tend to support that requirement for our main outcomes.

Still, the empirical credibility of the geographical variation described above also requires that people living in a municipality who became victims of the attack (either deceased or survivors) were in some way more 'exposed' to the event than people living in other municipalities. Several pieces of evidence support that basic contention. First, and most directly, personal and social connections are most likely between people from the same municipality, which may induce closer affinities with the victims. That conclusion is supported by the fact that respondents in the 2011 Local Democracy Survey were more likely to have attended a public event related to the attack if they resided in 'treated' municipalities (though they were not more likely to have become more interested in politics, follow news more closely, or become members of a political party). From that perspective, it also is important to note that local identities tend to be very strong in Norway: 

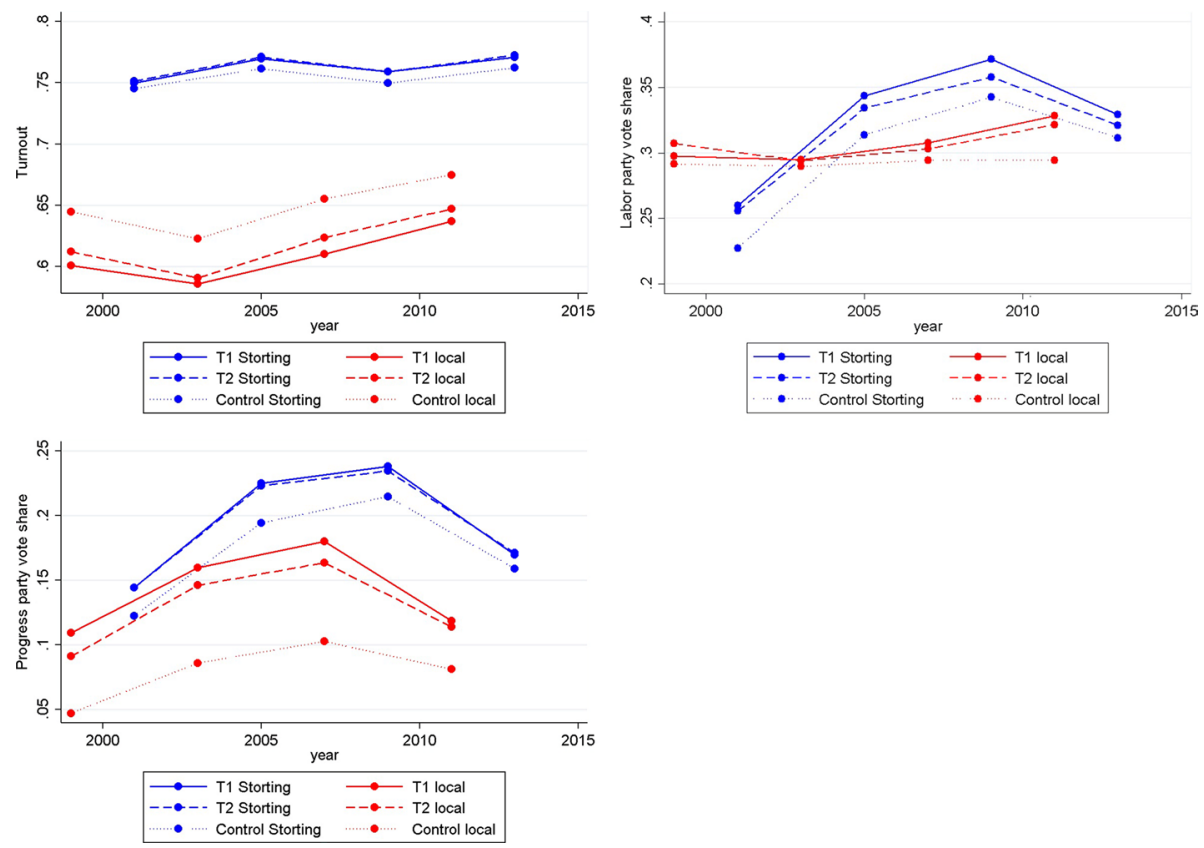

Fig. 2 Trends. Note: The figure presents the aggregate trends in voter turnout rates (top panel), Labour Party vote shares (middle panel) and Progress Party vote shares (bottom panel) across the four local and national elections surrounding the terrorist event under analysis. $T 1$ and $T 2$ refer to municipalities' 'treatment' status (i.e., inhabitants killed [T1], inhabitants present but survived [T2], and no inhabitants present [Control])

Most within-country migration takes place within municipal boundaries (Statistics Norway 2013) and only a very narrow majority of people feel some connection to people in neighboring municipalities (Frisvoll and Almås 2004). ${ }^{5}$ Second, news reports about specific individuals in Norway routinely include information about their municipality of residence, which highlights that such information is seen as capturing a salient feature of a person's identity. The same was true in reporting about the victims of the 22 July attack. In fact, basic information about the victims, which included their home municipality at the time, continues to be maintained online by two major Norwegian news outlets (NRK 2015; Verdens Gang 2015). Finally, local newspapers retain a substantial and stable circulation in Norway; a large share of people report reading district and local newspapers (Statistics Norway 2014). Such local media outlets tend to provide more information about local individuals, which implies that people in municipalities from which victims of the attack came would acutely be aware of those facts.

\footnotetext{
${ }^{5}$ Even so, the fact that people also are connected across municipal boundaries washes out any geographical treatment effects, in particular for smaller municipalities. Our estimates therefore can be interpreted as a lower bound.
} 
Table 2 Individual-level survey data on intended party choice 2010-2011

\begin{tabular}{lllll}
\hline & MinorLeft b/se & Labour b/se & Conserv b/se & Progress b/se \\
\hline 22July & 0.743 & $1.917^{* * *}$ & $0.808^{* *}$ & 0.932 \\
& $(0.136)$ & $(0.177)$ & $(0.083)$ & $(0.122)$ \\
Weeks & $0.998^{* *}$ & $0.996^{* * *}$ & $1.003^{* * *}$ & $0.998^{* *}$ \\
& $(0.001)$ & $(0.001)$ & $(0.001)$ & $(0.001)$ \\
Weeks * 22July & $1.027^{* *}$ & $0.982^{* * *}$ & $1.017^{* *}$ & $0.980^{* *}$ \\
& $(0.011)$ & $(0.005)$ & $(0.007)$ & $(0.009)$ \\
Constant & $0.068^{* * *}$ & $0.275^{* * *}$ & $0.094^{* * *}$ & $0.165^{* * *}$ \\
& $(0.012)$ & $(0.035)$ & $(0.010)$ & $(0.033)$ \\
Individual controls & Yes & Yes & Yes & Yes \\
Municipality f.e. & Yes & Yes & Yes & Yes \\
Depvar mean & 0.111 & 0.245 & 0.219 & 0.111 \\
Pseudo-R-sq & 0.073 & 0.040 & 0.072 & 0.083 \\
$\mathrm{~N}$ & 21430 & 21796 & 21515 & 21151 \\
\hline
\end{tabular}

$* p<0.10, * * p<0.05, * * * p<0.01$

22July is a dummy equal to 1 for the period following the terrorist attack, while Weeks counts the number of weeks before/after the event (set to 0 in the week of the 22 July). MinorLeft refers to the joint vote share of several smaller left-wing political parties excluding the Labour party. Individual controls include sex, age, education, income and professional activity. Data are available from January 2010 to December 2011. Coefficient estimates are in log odds form, and standard errors are clustered at the municipality level

\section{Results}

We start the discussion of our results by looking at the attack's immediate impact on individual-level intended party choices by exploiting data from political polls in an event-study framework. We then move to a difference-in-differences specification in order to examine the event's effects on party leader evaluations. Finally, we use aggregate-level vote shares in the medium and long terms by analyzing results from the 2011 municipal and 2013 national elections, respectively (also adopting a difference-in-differences specification).

\subsection{Intended party choice in the short-to-medium term (event study)}

Table 2 reports effects on individuals' intended party choices immediately after the attack. Coefficient estimates are presented in log odds form for ease of interpretation (a graphical representation using different polynomials is provided in Fig. 3). The top row of the first two columns in Table 2 indicates that the Labour Party witnessed a very strong and statistically significant jump in voter support in the immediate aftermath of the attack, whereas other left-wing parties saw their support among the populace decline. In terms of estimated effect magnitudes, Labour Party support nearly doubled (i.e., a 92\% increase) in the week of the attack whereas other left-wing parties witnessed a nearly $26 \%$ drop in voter support. Interestingly, however, the coefficient estimates on the interaction term reported in the third row indicates that the reverse pattern materialized in the weeks following the attack, i.e., the Labour Party gradually lost voter support whereas the other left-wing parties were on 

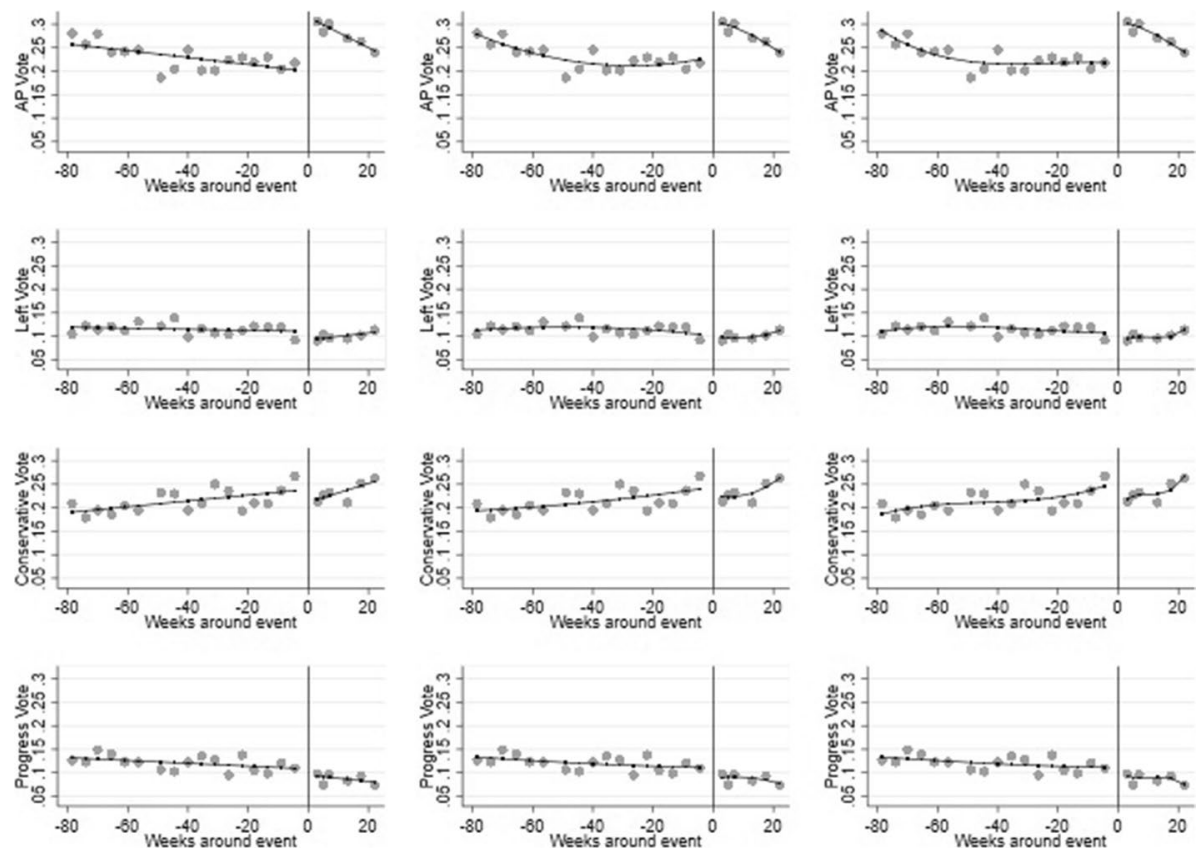

Fig. 3 Individual-level survey data on intended party choice using different polynomials. Note: The figure presents the results of estimating Eq. (1) using different polynomials for the running variable (Weeks). The left-hand column employs a linear local regression, while the middle right-hand column relies on quadratic and cubic functional forms. Each row contains the results for different parties going from the Labour Party (AP, top row) and the other main left-wing parties, to the Conservative Party and the Progress Party (bottom row)

an upward trajectory. ${ }^{6}$ On the other side of the ideological spectrum, we observe that both main right-wing parties lost voter support in the immediate aftermath of the attack (roughly $19 \%$ for the Conservative Party and 7\% for the Progress Party). Yet, the Conservative Party started gaining support in subsequent weeks, whereas the far-right Progress Party gradually lost support as the weeks passed. ${ }^{7}$ Overall, the results strongly suggest shifts within the left-right political blocs in Norway-rather than shifts between those blocs-in the aftermath of 22 July. We return to this below.

Table A.4 in the online appendix indicates that changes in the event window-including adopting a balanced window ( -22 to +22 weeks around the event) and restricting the analysis to the event year ( -30 to +22 weeks around the event) - generates essentially the same coefficient estimates. Optimal window sizes following Calonico et al. (2017) and Calonico et al. (2019) turn out to be very narrow and generally cover fewer than two surveys prior to the event. While estimation using such minimal windows lacks empirical credibility, doubling the window again leaves our inferences unaffected. Finally, a placebo check using 22 July 2010 as the event date reveals no statistically significant shift at the

\footnotetext{
6 This reversal in the various left-wing parties' fortunes in the weeks following the attack tended to be strongest in municipalities more directly affected by the attack (see Fig. A.1 in the online appendix).

7 Again, the Progress Party's loss was strongest in municipalities more directly affected by the attack (see Fig. A.1 in the online appendix).
} 
Table 3 Party leader evaluations 2010-2011

\begin{tabular}{lllllll}
\hline & Labour b/se & SLP b/se & V b/se & KRF b/se & Conserv b/se & Progress b/se \\
\hline T1 & -0.041 & 0.003 & 0.023 & -0.065 & 0.053 & 0.029 \\
& $(0.170)$ & $(0.165)$ & $(0.167)$ & $(0.141)$ & $(0.118)$ & $(0.182)$ \\
T2 & -0.107 & 0.060 & 0.197 & 0.020 & 0.067 & 0.015 \\
June 2010 & $(0.190)$ & $(0.180)$ & $(0.169)$ & $(0.154)$ & $(0.131)$ & $(0.203)$ \\
& -0.053 & $0.253^{* * *}$ & 0.046 & $-0.460^{* * *}$ & -0.061 & -0.044 \\
Dec 2011 & $(0.085)$ & $(0.063)$ & $(0.066)$ & $(0.073)$ & $(0.066)$ & $(0.077)$ \\
& $0.713^{* * *}$ & 0.086 & $0.476^{* * *}$ & $0.241^{*}$ & $0.259^{* *}$ & $-0.687^{* * *}$ \\
Constant & $(0.163)$ & $(0.157)$ & $(0.146)$ & $(0.139)$ & $(0.116)$ & $(0173)$ \\
& $3.828^{* * *}$ & $3.062^{* * *}$ & $3.279^{* * * *}$ & $3.570 * * *$ & $4.046 * * *$ & $3.916^{* * *}$ \\
Individual controls & $(0.153)$ & $(0.159)$ & $(0.138)$ & $(0.149)$ & $(0.133)$ & $(0.143)$ \\
Municipality f.e. & Yes & Yes & Yes & Yes & Yes & Yes \\
Depvar mean & 4.007 & 3.172 & 3.384 & 3.400 & 4.371 & 3.313 \\
R-sq & 0.188 & 0.188 & 0.234 & 0.246 & 0.203 & 0.191 \\
$\mathrm{~N}$ & 2868 & 2685 & 2472 & 2706 & 2836 & 2847 \\
\hline
\end{tabular}

$* p<0.10, * * p<0.05, * * * p<0.01$

$T 1$ and $T 2$ refer to municipalities' 'treatment' status (i.e. inhabitants killed [T1], inhabitants present but survived [T2], and no inhabitants present [Control]). Individual controls include sex, age, education, income and professional activity. Data are available for June 2010, June 2011 and December 2011 (with June 2011 used as the reference category). Standard errors are clustered at the municipality level

event date for any of the political parties included in our analysis (see Table A.3 in the online appendix). That evidence strongly suggests that our findings are indeed driven by the actual terror attack on 22 July 2011.

\subsection{Assessments of party leaders (DiD)}

In Table 3, we investigate how Norwegians' assessments of political party leaders were affected by the terrorist attack. because of data availability, the analysis includes the leaders of two left-wing parties (Labour and the Socialist Left Party SLP), two centrist parties (Venstre V and Christian KRF) and two right-wing parties (the Conservative Party and the Progress Party). They are presented in order of their positions on the left-right political spectrum. Given that we have only three observations (i.e., June 2010, June 2011 and December 2011), we cannot rely on the event study framework. Instead, we implement a difference-in-differences approach [see Eq. (2)], which allows us to evaluate whether any political shifts were particularly strong in municipalities that suffered more in the attack ( $T 1$ and $T 2$ ) than the rest of the country.

Table 3 first of all reveals no differential effects in leader evaluations depending on treatment intensity (both $T 1$ and $T 2$ carry insignificant point estimates). The coefficient estimates for "Dec 2011" nonetheless provide important insights. Those coefficients indicate the difference between party leader evaluations in December 2011 (i.e., the first survey asking questions after the event) and June 2011 (i.e., the reference category, and the last survey asking the questions before the event). The results here indicate that the Labour Party leader-who also was the Prime Minister at the time of the attack-witnessed a 
Table 4 Turnout and party vote shares in local elections 1999-2011

\begin{tabular}{|c|c|c|c|c|c|c|}
\hline & (1) & (2) & (3) & (4) & (5) & (6) \\
\hline & Turnout & MinorLeft & Labour & Other & Conserv & Progress \\
\hline \multirow[t]{2}{*}{$\mathrm{T} 1$} & 0.005 & $-0.028 * * *$ & $0.030 * *$ & -0.008 & $0.043 * * *$ & $-0.037 * * *$ \\
\hline & $(0.005)$ & $(0.006)$ & $(0.013)$ & $(0.013)$ & $(0.011)$ & $(0.009)$ \\
\hline \multirow[t]{2}{*}{$\mathrm{T} 2$} & 0.004 & $-0.010 * *$ & 0.016 & -0.001 & $0.016^{*}$ & $-0.021 * * *$ \\
\hline & $(0.003)$ & $(0.004)$ & $(0.010)$ & $(0.012)$ & $(0.009)$ & $(0.006)$ \\
\hline \multirow[t]{2}{*}{1999} & $-0.011 * * *$ & $0.008 * * *$ & -0.002 & $0.038 * * *$ & $0.018 * * *$ & $-0.063 * * *$ \\
\hline & $(0.002)$ & $(0.002)$ & $(0.006)$ & $(0.007)$ & $(0.005)$ & $(0.004)$ \\
\hline \multirow[t]{2}{*}{2003} & $-0.032 * * *$ & $0.039 * * *$ & -0.007 & -0.007 & $-0.008^{* *}$ & $-0.018 * * *$ \\
\hline & $(0.002)$ & $(0.003)$ & $(0.005)$ & $(0.005)$ & $(0.003)$ & $(0.003)$ \\
\hline \multirow[t]{2}{*}{2011} & $0.020 * * *$ & $-0.007 * * *$ & -0.000 & $-0.020 * *$ & $0.051 * * *$ & $-0.024 * * *$ \\
\hline & $(0.002)$ & $(0.002)$ & $(0.007)$ & $(0.008)$ & $(0.006)$ & $(0.004)$ \\
\hline \multirow[t]{2}{*}{ Constant } & $0.640 * * *$ & $0.053 * * *$ & $0.298 * * *$ & $0.383 * * *$ & $0.136 * * *$ & $0.130 * * *$ \\
\hline & $(0.001)$ & $(0.001)$ & $(0.003)$ & $(0.003)$ & $(0.002)$ & $(0.002)$ \\
\hline Municipality f.e. & Yes & Yes & Yes & Yes & Yes & Yes \\
\hline Depvar mean & 0.64 & 0.06 & 0.30 & 0.39 & 0.15 & 0.10 \\
\hline R-sqr & 0.859 & 0.799 & 0.781 & 0.863 & 0.814 & 0.834 \\
\hline $\mathrm{N}$ & 1720 & 1720 & 1720 & 1720 & 1720 & 1720 \\
\hline
\end{tabular}

$* p<0.10, * * p<0.05, * * * p<0.01$

$T 1$ and $T 2$ refer to municipalities' 'treatment' status (i.e. inhabitants killed [T1], inhabitants present but survived [T2], and no inhabitants present [Control]). 2007 is used as the reference category. Standard errors are clustered at the municipality level

statistically significant aggregate boost in his performance assessment following the event. That increase substantively was very meaningful as it reflects more than 0.7 points on a scale running from 1 to 6 (where 1 is the lowest grade and 6 is the best grade). Interestingly, the same is not true for the leader of the left-wing Socialist Left Party (SLP). Hence, the findings in Table 3 are consistent with voters-at least in the medium run-reallocating their political support within the left-right political bloc. A similar observation arises for the right bloc. Indeed, while the far-right Progress Party's leadership lost support, the leadership of other right-leaning conservative parties was evaluated more positively after the attack. Overall, consistent with growing personalization of party politics, the changes in leader evaluations thus closely mirror the changes in intended vote choices as documented in Table 2.

\subsection{Party choice in the medium term: municipal election 2011 (DiD)}

The first election following the attack on 22 July was a municipal election, which took place on 12 September 2011. That day was around two months after the attack, providing an opportunity to investigate the attack's political effects in the medium term. Still, it may be misleading simply to compare vote shares in that election to the previous local election four years earlier because many factors may have influenced the aggregate political landscape over that period. We therefore again rely on a difference-in-differences strategy comparing municipalities that suffered more casualties in the attack ( $T 1$ and $T 2$ ) to the rest of the country. 
Table 4 shows the results. In the first column, we report estimates for voter turnout, while the remaining columns we investigate party vote shares (with parties ordered by their positions on the left-right political spectrum). The large, positive coefficient on the 2011 dummy in the first column shows that overall turnout was two percentage points higher than in 2007. One interpretation is that the attack had a positive effect on overall voter turnout rates in Norway, though not differentially across the more intensely affected municipalities than in the rest of the country (both $T 1$ and $T 2$ carry insignificant point estimates). A positive effect on turnout is consistent with earlier findings that terrorist events with extreme political motives mobilize voters (and elites). Robbins et al. (2013, p. 495) indeed argue that terrorist attacks trigger emotional responses that lead people to "ascribe greater salience to proximate political events", which induces greater participation in upcoming elections.

The remaining columns in Table 4 show that the attack had a substantial impact on party vote shares. Specifically, the main left-wing parties aside from the Labour Party lost substantially [ 2.8 percentage points in $T 1$ municipalities and 0.1 percentage points in $T 2$ municipalities; see Column (2)], while the Labour Party-which was the direct target of the attacks-experienced an increase of a similar magnitudes [ 3.0 percentage points in $T 1$ municipalities and 1.6 percentage points in $T 2$ municipalities, see Column (3)]. A natural interpretation is that voters on the left shifted their votes partly to Labour, which is consistent with the results of our event-based analysis discussed above. Interestingly, a similar reallocation of vote shares is observed on the right side of the political spectrum. The Conservative Party gained [4.3 percentage points in $T 1$ municipalities and 1.6 percentage points in $T 2$ municipalities; see Column (5)] while the Progress Party lost equivalent amounts of support [3.7 percentage points in $T 1$ municipalities and 2.1 percentage points in $T 2$ municipalities; see Column (6)]. All but one of the estimates for party choices are statistically significant at conventional levels. The pattern of the coefficients suggest a substantial reallocation of political support within the left-right political blocs rather than between them.

Naturally, an alternative explanation could be that our results reflect a shift in the composition of the voting electorate rather than individual voters changing their preferences. That is, following the attack, Labour supporters decided to turn out to vote in larger numbers, while Progress Party supporters more often than before decided to abstain from voting. That alternative explanation is perfectly consistent with our key argument that the attack induced observable political implications (and likewise is relevant to all other previous aggregate-level work on the link between terrorism and vote choices). However, our individual-level results reported above suggest strongly that voters on the left and right sides of the political spectrum also changed their parties of choice (at the very least in the immediate aftermath of the attack). That conclusion is corroborated by Bergh and Bjørklund (2013), who analyzed answers to questions about the attacks in the official election survey. A central finding is that the Labour Party gained new voters who stated that they were affected by the attacks, while the Progress Party lost such voters. The authors also find a reallocation of voters within the left and right blocs; voters moved towards the center (i.e., towards Labour and the Conservatives and away from the Socialist Left Party and the Progress Party, respectively).

It is important to point out that our findings are not explained by the content and nature of the election campaign, since the political parties agreed not to let the attacks become a dominating campaign issue. They also are not explained by sudden shifts in parties' policy platforms, although taking an aggressive anti-immigration stance-which aligned with the terrorist's preferences-was considered to be more difficult in the media and public debate 
Table 5 Turnout and party vote shares in parliamentary elections 2001-2013

\begin{tabular}{|c|c|c|c|c|c|c|}
\hline & (1) & (2) & (3) & (4) & (5) & (6) \\
\hline & Turnout & MinorLeft & Labour & Other & Conserv & Progress \\
\hline \multirow[t]{2}{*}{$\mathrm{T} 1$} & 0.001 & $-0.012 * * *$ & $-0.013 * * *$ & $0.030 * * *$ & $0.009 * *$ & $-0.015^{* * *}$ \\
\hline & $(0.002)$ & $(0.004)$ & $(0.004)$ & $(0.007)$ & $(0.005)$ & $(0.004)$ \\
\hline \multirow[t]{2}{*}{$\mathrm{T} 2$} & 0.002 & $-0.004^{*}$ & $-0.012 * * *$ & $0.028 * * *$ & -0.001 & $-0.011 * * *$ \\
\hline & $(0.002)$ & $(0.002)$ & $(0.003)$ & $(0.005)$ & $(0.004)$ & $(0.003)$ \\
\hline \multirow[t]{2}{*}{2001} & $-0.006^{* * *}$ & $0.056^{* * * *}$ & $-0.111 * * *$ & $0.125 * * *$ & $0.022 * * *$ & $-0.092 * * *$ \\
\hline & $(0.001)$ & $(0.001)$ & $(0.002)$ & $(0.004)$ & $(0.002)$ & $(0.002)$ \\
\hline \multirow[t]{2}{*}{2005} & $0.012 * * *$ & $0.025 * * *$ & $-0.027 * * *$ & $0.051 * * *$ & $-0.032 * * *$ & $-0.017 * * *$ \\
\hline & $(0.001)$ & $(0.001)$ & $(0.001)$ & $(0.002)$ & $(0.001)$ & $(0.001)$ \\
\hline \multirow[t]{2}{*}{2013} & $0.012 * * *$ & $-0.015 * * *$ & $-0.029 * * *$ & $0.014 * * *$ & $0.085 * * *$ & $-0.055^{* * *}$ \\
\hline & $(0.001)$ & $(0.001)$ & $(0.002)$ & $(0.003)$ & $(0.002)$ & $(0.002)$ \\
\hline \multirow[t]{2}{*}{ Constant } & $0.754 * * *$ & $0.058 * * *$ & $0.351 * * *$ & $0.241 * * *$ & $0.127 * * *$ & $0.224 * * *$ \\
\hline & $(0.001)$ & $(0.001)$ & $(0.001)$ & $(0.001)$ & $(0.001)$ & $(0.001)$ \\
\hline Municipality f.e. & Yes & Yes & Yes & Yes & Yes & Yes \\
\hline Depvar mean & 0.76 & 0.07 & 0.31 & 0.29 & 0.15 & 0.18 \\
\hline R-sqr & 0.889 & 0.884 & 0.953 & 0.930 & 0.939 & 0.912 \\
\hline $\mathrm{N}$ & 1718 & 1718 & 1718 & 1718 & 1718 & 1718 \\
\hline
\end{tabular}

$* p<0.10, * * p<0.05, * * * p<0.01$

$T 1$ and $T 2$ refer to municipalities' 'treatment' status (i.e. inhabitants killed [T1], inhabitants present but survived [T2], and no inhabitants present [Control]). 2009 is used as the reference category. Standard errors are clustered at the municipality level

after the attacks. Furthermore, one might worry that municipalities with citizens participating in the Labour Party's youth camp were characterized by specific political sentiments not present in other municipalities. Entering municipality-specific linear time trends allows municipalities to be on distinct temporal trends and might therefore help address that concern. Although standard errors as expected become larger in this very demanding specification given that we have only a few observations, the main coefficient estimates go in the same direction (see Table A.1 in the online appendix). Finally, as can be seen from Table 1, the Labour Party's vote share in the previous local election (held in 2007) was very similar across the treatment groups (i.e., roughly 30-31\%). Hence, we do not expect pre-attack support for the Labour Party to undermine the validity of our main results. ${ }^{8}$

\subsection{Party choice in the long term: national election 2013 (DiD)}

The second election in Norway after the attack took place for the national parliament ('Stortinget') in September 2013-approximately two years and two months after the attack-providing an opportunity to assess the persistence of the political effects of 22 July observed above in the long term.

\footnotetext{
${ }^{8}$ Two voting experiments took place during the 2011 elections: In 10 municipalities, ballots could be cast over the internet and in 18 municipalities, the voting age was lowered to 16 (instead of 18). Both experiments included some municipalities from all three groups examined herein. Dropping the 28 municipalities from the analysis makes no practical difference in the results.
} 
Table 5 reports the results for the 2013 parliamentary elections. Voter turnout is observed to be higher in 2013 than in the reference year (2009), but as before no differences are evident depending on treatment intensity [see Column (1)]. As before, the parties on the left other than Labour and the right-wing Progress Party witnessed declines in vote shares, while the Conservative Party gained-see Columns (2), (5) and (6), respectively. The coefficient estimates, however, tend to be substantially smaller (with effects around one percentage point in $T 1$ municipalities), which is to be expected if effects dissipate with time. Interestingly, the findings for the Labour Party have reversed, and show that the party lost vote share in the municipalities with the heaviest losses from the attack, relative to the rest of the country [see Column (3)]. Note that the loss is not a simple reversal of the boost the party received in the local elections of 2011, since we include only national election results in these estimations. One potential explanation may be the criticism the Labour Party - as leader of the government—faced in the aftermath of the August 2012 "Gjørv report". That report was produced by a fact-finding commission assembled to review and learn from the terrorist attack. The report criticized some of the authorities' response to the attack sharply (in particular, the time it took police to reach the island), and argued that the attack might have been preventable if security measures approved previously had been implemented properly. ${ }^{9}$

Before concluding, it is worth observing that voters appear to react similarly across treatment groups in the individual-level leader evaluation analysis (Table 3), whereas we find significant differences across treatment groups when evaluating the aggregate vote choice results (Tables 4 and 5). One potential explanation for the diverging results might be linked to the relative importances of the two decisions, since casting a vote in an election arguably is more important than responses to a leadership evaluation survey. That difference might affect what is taken into account during each of the decision-making processes. The pattern of our results thus might suggest that the local impact of terrorist events may carry more weight in the former decision process, while the general impact of terrorist events may be more relevant to the latter. Unfortunately, our data do not allow us to explore this in more detail.

\section{Conclusion}

Our analysis evaluated the political implications of a terrorist act motivated by an extreme (right-wing) political ideology. Inspired by the rising personalization of party politics (McAllister 2016), we thereby push the literature by evaluating the extent to which party leader assessments can provide a potential mechanism underlying public responses in terms of both opinion polls and voting outcomes.

Analyzing voters' political responses to the extreme right-wing ideological terrorist attack in Norway on 22 July 2011, we do not find a differential effect on voter turnout rates in municipalities that suffered more in the attack. In sharp contrast, we find substantial and precise effects on party choices - up to four percentage points in the medium term, more moderate in the long term — as well as assessments of party leaders. The latter effects overall provide a close analogue to the former, since in both cases we observe that voters

\footnotetext{
${ }^{9}$ As before, including municipality-specific time trends give largely similar results, see Table A.2 in the online appendix.
} 
reallocate their political support within rather than between the left-right political blocs. Hence, our findings are consistent with the notion that the perceived responses of party leaders to terrorist events provide an important lens for voters' (political) interpretation of such violent events. Our results contrast with the literature on religious/separatist violence, which has tended to find movement between political blocs. We consider it an important avenue for further - and explicitly comparative-research to delve into the potential underlying mechanisms for that difference, which might include the nature of the party system, the nature of the terrorist incident or the post-event information environment. While our data do not allow addressing those important issues, more in-depth analysis of them would be essential to understand when, why, and how specific patterns of findings can be generalized (or not) across settings. Our findings also can be interpreted partly as a "rally-roundthe-flag" effect, such that support for the government is strengthened as a consequence of a dramatic event (Baker and Oneal 2001; Eichenberg and Stoll 2006; Colaresi 2007). However, the substantive shifts within the left-right political blocs show that more is going on in our setting than a mere support-"rallying" effect.

Our analysis naturally has a number of limitations, which suggest important potential avenues for further research. First, while 22 July was an act of extreme right-wing terrorism, it was not a symptom of a persistent and well-organized right-wing terrorist threat within Norway. That observation raises the question of how our results would be affected by a more persistent terrorist threat with extreme political inspiration (such as, for instance, the Rote Armee Fraction in 1970s' Germany or Belgium's Communist Combatant Cells in the mid-1980s). Answering such questions will allow us to learn more about exactly how terrorist attacks are understood in the voting population, and how that understanding translates into actual voting behavior. Second, even though anti-terrorism is a central government responsibility, electoral accountability might be less relevant in case of lone wolf terror events (as most people are likely to understand that it is hard to protect society against lone wolf terrorists). A comparison of lone wolf versus organizational terrorism thus is an important avenue for further research that unravels the precise role of government's (perceived) accountability in such events. Finally, future research should assess the extent to which the leadership effects observed herein are driven by, for instance, voters' feelings of identification with political parties or more direct effects of leader personality and value representation.

Acknowledgements Open Access funding provided by Norwegian Business School BI. We gratefully acknowledge Idar Eidset from Respons Analyse for assistance with the polling data. Data were obtained from Statistics Norway, the Norwegian Social Science Data Services (NSD), and Respons Analyse, though all interpretations are our sole responsibility. The first author gratefully acknowledges FWO Vlaanderen (Grant Number G.000218N) for financial support. We also thank Simen Markussen for suggesting this research project as well as two anonymous referees, the editor, Andreas Kotsadam and Rune Sørensen for valuable comments.

Open Access This article is licensed under a Creative Commons Attribution 4.0 International License, which permits use, sharing, adaptation, distribution and reproduction in any medium or format, as long as you give appropriate credit to the original author(s) and the source, provide a link to the Creative Commons licence, and indicate if changes were made. The images or other third party material in this article are included in the article's Creative Commons licence, unless indicated otherwise in a credit line to the material. If material is not included in the article's Creative Commons licence and your intended use is not permitted by statutory regulation or exceeds the permitted use, you will need to obtain permission directly from the copyright holder. To view a copy of this licence, visit http://creativecommons.org/licenses/by/4.0/. 


\section{References}

Arce, D. G. (2019). On the human consequences of terrorism. Public Choice, 178(3), 371-396.

Arvanitidis, P., Economou, A., \& Kollias, C. (2016). Terrorism's effects on social capital in european countries. Public Choice, 169(3), 231-250.

Ashworth, S., Bueno de Mesquita, E., \& Friedenberg, A. (2018). Learning about voter rationality. American Journal of Political Science, 62(1), 37-54.

Baker, W., \& Oneal, J. (2001). Patriotism or opinion leadership: The nature and origins of the rally round the flag effect. Journal of Conflict Resolution, 45, 661-687.

Bandyopadhyay, S., Sandler, T., \& Younas, J. (2018). Trade and terrorism: A disaggregated approach. Journal of Peace Research, 55(5), 656-670.

Baum, M. A. (2002). The constituent foundations of the rally-round-the-flag phenomenon. International Studies Quarterly, 46(2), 263-298.

Bergh, J., \& Bjørklund, T. (2013). Lokalvalget i skyggen av 22. Juli. In J. Bergh \& D. A. Christensen (Eds.), Et robust lokaldemokrati: Lokalvalget i skyggen av 22. juli 2011 (pp. 21-43). Oslo: Abstrakt Forlag.

Berrebi, C., \& Klor, E. (2008). Are voters sensitive to terrorism? Direct evidence from the Israeli electorate. American Political Science Review, 102(3), 279-301.

Berrebi, C., \& Ostwald, J. (2011). Earthquakes, hurricanes, and terrorism: Do natural disasters incite terror? Public Choice, 149(3), 383-403.

Berrebi, C., \& Yonah, H. (2016). Terrorism and philanthropy: The effect of terror attacks on the scope of giving by individuals and households. Public Choice, 169(3), 171-194.

Birkelund, G., Ugreninov, E., Chan, T., Midtbøen, A., \& Rogstad, J. (2019). Do terrorist attacks affect ethnic discrimination in the labour market? Evidence from two randomised field experiments. British Journal of Sociology, 70(1), 241-260.

Blomberg, S., Hess, G., \& Tan, D. (2011). Terrorism and the economics of trust. Journal of Peace Research, 48(3), 383-398.

Bozzoli, C., \& Mueller, C. (2011). Perceptions and attitudes following a terrorist shock: Evidence from the UK. European Journal of Political Economy, 27(1), 89-106.

Calonico, S., Cattaneo, M., Farrell, M., \& Titiunik, R. (2017). rdrobust: Software for regression discontinuity designs. Stata Journal, 17(2), 372-404.

Calonico, S., Cattaneo, M., Farrell, M., \& Titiunik, R. (2019). Regression discontinuity designs using covariates. Review of Economics and Statistics, 101(3), 442-451.

Chowanietz, C. (2011). Rallying around the flag or railing against the government? Political parties' reactions to terrorist acts. Party Politics, 17(5), 673-698.

Colaresi, M. (2007). The benefit of the doubt: Testing an informational theory of the rally effect. International Organization, 61(1), 99-143.

Echebarria-Echabe, A., \& Fernandez-Guede, E. (2006). Effects of terrorism on attitudes and ideological orientation. European Journal of Social Psychology, 36(2), 259-265.

Economou, A., \& Kollias, C. (2019). Security policy preferences of eu citizens: Do terrorist events affect them? Public Choice, 178(3), 445-471.

Eichenberg, R., \& Stoll, R. (2006). War president: The approval ratings of George W. Bush. Journal of Conflict Resolution, 50, 783-808.

Enders, W., \& Sanders, T. (2012). The political economy of terrorism. Cambridge: Cambridge University Press.

Finseraas, H., \& Listhaug, O. (2013). It can happen here: The impact of the Mumbai terror attacks on public opinion in Western Europe. Public Choice, 156(1-2), 213-228.

Finseraas, H., Listhaug, O., \& Kotsadam, A. (2011). Did the murder of Theo van Gogh change Europeans' immigration policy preferences? Kyklos, 64(3), 396-409.

Frisvoll, S., \& Almås, R. (2004). Kommunestruktur mellom fornuft og følelser. betydningen av tilhørighet og identitet i spørsmål om kommunesammenslutning. Technical report 5, Bygdeforskning - Rapport.

Gaibulloev, K., Oyun, G., \& Younas, J. (2019). Terrorism and subjective financial well-being: Micro-level evidence from Pakistan. Public Choice, 178(3), 493-512.

Gaibulloev, K., \& Sandler, T. (2011). The adverse effect of transnational and domestic terrorism on growth in Africa. Journal of Peace Research, 48(3), 355-371.

Gaibulloev, K., \& Sandler, T. (2019). Terrorism and affinity of nations. Public Choice, 178(3), 329-347.

Gartner, S. (2014). Making the international local: The terrorist attack on the USS cole, local casualties, and media coverage. Political Communication, 21(2), 139-159. 
Gartner, S., Segura, G., \& Wilkening, M. (1997). All politics are local: Local losses and individual attitudes toward the Vietnam war. Journal of Conflict Resolution, 41(5), 669-694.

Gassebner, M., \& Luechinger, S. (2011). Lock, stock, and barrel: A comprehensive assessment of the determinants of terror. Public Choice, 149(3), 235.

Getmansky, A., \& Zeitzoff, T. (2014). Terrorism and voting: The effect of rocket threat on voting in Israeli elections. American Political Science Review, 108(3), 588-604.

Geys, B., \& Qari, S. (2017). Will you still trust me tomorrow? The causal effect of terrorism on social trust. Public Choice, 173, 289-305.

Gleditsch, K. S., \& Polo, S. M. T. (2016). Ethnic inclusion, democracy, and terrorism. Public Choice, 169(3), 207-229.

Gould, E., \& Klor, E. (2016). The long-run effect of 9/11: Terrorism, backlash, and the assimilation of Muslim immigrants in the West. Economic Journal, 126(597), 2064-2114.

Hirsch-Hoefler, S., Canetti, D., Rapaport, C., \& Hobfoll, S. (2016). Conflict will harden your heart: Exposure to violence, psychological distress, and peace barriers in Israel and Palestine. British Journal of Political Science, 46(4), 845-859.

Holman, M. R., Merolla, J. L., \& Zechmeister, E. J. (2016). Terrorist threat, male stereotypes, and candidate evaluations. Political Research Quarterly, 69(1), 134-147.

Jakobsson, N., \& Blom, S. (2014). Did the 2011 terror attacks in Norway change citizens' attitudes towards immigrants? International Journal of Public Opinion Research, 26(4), 475-486.

Kibris, A. (2011). Funerals and elections: The effects of terrorism on voting behavior in Turkey. Journal of Conflict Resolution, 55(2), 220-247.

Kolås, A. (2017). How critical is the event? Multicultural Norway after 22 July 2011. Social Identities, 23(5), 518-532.

Krieger, T., \& Meierrieks, D. (2011). What causes terrorism? Public Choice, 147(1-2), 3-27.

McAllister, I. (2016). Candidates and voting choice. http://politics.oxfordre.com/view/10.1093/acref ore/9780190228637.001.0001/acrefore-9780190228637-e-73.

Merolla, J., \& Zechmeister, E. (2013). Evaluating political leaders in times of terror and economic threat: The conditioning influence of politician partisanship. Journal of Politics, 75(3), 599-612.

Merolla, J. L., \& Zechmeister, E. J. (2009a). Democracy at risk: How terrorist threats affect the public. Chicago: University of Chicago Press.

Merolla, J. L., \& Zechmeister, E. J. (2009b). Terrorist threat, leadership, and the vote: Evidence from three experiments. Political Behavior, 31(4), 575-601.

Montalvo, J. G. (2011). Voting after the bombings: A natural experiment on the effect of terrorist attacks on democratic elections. Review of Economics and Statistics, 93(4), 1146-1154.

Neumayer, E., \& Plümper, T. (2016). Spatial spill-overs from terrorism on tourism: Western victims in islamic destination countries. Public Choice, 169(3), 195-206.

Norwegian Directorate of Health. (2012). The medical response to the terrorist incidents of 22 July 2011. Technical report, Norwegian Directorate of Health.

NRK. (2015). 22. juli-rettssaken: Dødsofrene. http://www.nrk.no/227/fakta/dodsofre. Retrieved March 07, 2015.

Oslo Tingrett. (2011). Fengslingskjennelse Anders Behring Breivik. Technical report, Oslo tingrett.

Peffley, M., Hutchison, M., \& Shamir, M. (2015). The impact of persistent terrorism on political tolerance: Israel 1980 to 2011. American Political Science Review, 109(4), 817-832.

Piazza, J. A. (2016). Oil and terrorism: An investigation of mediators. Public Choice, 169(3), 251-268.

Robbins, J., Hunter, L., \& Murray, G. (2013). Voters versus terrorists: Analyzing the effect of terrorist events on voter turnout. Journal of Peace Research, 50(4), 495-508.

Shughart, W. F, I. I. (2006). An analytical history of terrorism, 1945-2000. Public Choice, 128(1), 7-39.

Sinclair, S., \& LoCicero, A. (2010). Do fears of terrorism predict trust in government? Journal of Aggression, Conflict and Peace Research, 2, 57-68.

Sinkkonen, T. (2016). Can political leaders make a difference? Norwegian versus spanish experiences in responding to terrorist attacks. Studies in Conflict \& Terrorism, 39(4), 326-341.

Statistics Norway. (2013). Migrations 2013. http://www.ssb.no/en/befolkning/statistikker/flytting. Accessed 26 Apr 2019.

Statistics Norway. (2014). Norsk mediebarometer 2014. Statistical analyses. https://www.ssb.no/223832/ norsk-mediebarometer-2014. Accessed 26 Apr 2019.

Stormark, K. (2011). Da terroren rammet Norge: 189 minutter som rystet verden. Oslo: Kagge Forlag. 
Thoresen, S., Aakvaag, H., Wentzel-Larsen, T., Dyb, G., \& Hjemdal, O. (2012). The day Norway cried: Proximity and distress in Norwegian citizens following the 22nd July 2011 terrorist attacks in Oslo and on Utøya Island. European Journal of Psychotraumatology, 3(1), 19709-19719.

Verdens Gang. (2015). Slik minnes vi vi våre kjære. http://www.vg.no/nyheter/innenriks/terrorangrepet/ minneord. Retireved March 07, 2015.

Wollebæk, D., Enjolras, B., Steen-Johnsen, K., \& Ødegård, G. (2012). After Utøya: How a high-trust society reacts to terror-trust and civic engagement in the aftermath of July 22. PS: Political Science and Politics, 45(1), 32-37.

Publisher's Note Springer Nature remains neutral with regard to jurisdictional claims in published maps and institutional affiliations. 